L. V. KRIVOBOKOV, D. V. DUNAIEV, A. V. DEMCHENKO

\title{
DETERMINATION OF A STATISTICAL SIMILARITY CRITERION FOR SOLID- PROPELLANT ENGINE TRYOUT CONDITIONS
}

\author{
Yuzhnoye State Design Office \\ 3 Krivorozhskaya St., Dnipro 49008,Ukraine; e-mail: dimor9diit@gmail.com
}

\begin{abstract}
This paper considers an example of calculating a statistical similarity criterion for solid-propellant engine five-parameter tryout conditions. The paper presents covariation and correlation matrices, their eigenvalues, and a statistical similarity criterion for solid-propellant engine tryout conditions calculated from the input data obtained in flight tests and ground tryout (firing bench tests). When obtaining input data, the classical approach requires the elimination of rows and columns containing missing values, which is unacceptable in the case of small samples and a high measurement cost. Because of this, it is proposed to replace the missing values of a parameter with its arithmetic mean. Since the principal components method considered in the paper is most efficient when all components are measured in the same units, it is proposed to normalize the input statistics. On normalization, all input data are converted into dimensionless quantities, but for large parameter values iterative procedures are possible (for example, the Jacobi method). After obtaining the covariance and correlation matrices for the flight tests and the ground tryout, their eigenvalues are calculated. Further, in order to construct a variation series of the eigenvalues of both matrices for the flight tests and the ground tryout, it is recommended to use the criterion of the maximum value of the eigenvalue from the series considered. This approach somewhat reduces calculation reliability, but it is quite applicable for practical calculations of a statistical similarity criterion from solidpropellant engine input data. The calculated statistical similarity criterion is compared with the value of the Harington desirability function, which confirms its applicability.
\end{abstract}

Keywords statistical criterion, dispersion, principal components method, solid-propellant engine, covariation matrix.

1. Krivobokov L. V., Dunaiev D. V., Demchenko A. V. Estimation of the adequacy of conditions for the development of rocketry hardware as complex systems using the theory of statistical similarity (in Russian). Teh. Meh. 2017. No. 3. Pp. 64-71.

2. Krivobokov L. V., Dunaiev D. V., Demchenko A. V. Determination of the adequacy of space launch vehicle system development conditions using a statistical similarity criterion (in Russian). Teh. Meh. 2018. No. 4. Pp. $119-125$.

3. Ayvazyan S. A., Enyukov E. S., Meshalkin L. D. Applied Statistics. Basics of Simulation and Data Preprocessing (in Russian). Moscow: Finansy i Statistika, 1983. $471 \mathrm{pp}$.

4. Kendall M., Stewart A. Volume 3: Multidimensional Statistical Analysis and Time Series (in Russian). Translated from English. A. N. Kolmogorov (Ed.). Moscow: Nauka, 1976. 736 pp.

5. Iterative methods for the solution of systems of liner algebraic equations. Jacobi method (in Russian). http://bigor.bmstu.ru/?cnt/?doc=Parallel/ch030203.mod (last accessed on Apr. 18, 2019).

6. Harrington, E. C. The desirable function. Industry Quality Control. 1965. V. 21. No. 10. Pp. 494-498.

Received on June 6, 2019, in final form on September 23, 2019 